\title{
Effective Application of Information Technology in Contemporary Art Education and Teaching
}

\author{
Xiaohua Ge \\ Huanghe Science and Technology College \\ Zhengzhou, China, 450063
}

\begin{abstract}
With continuous development of social science and new technology, information technology has many new breakthroughs. Meanwhile, it is also widely applied in contemporary art education and teaching field. Information technology is becoming more and more mature. From the aspect of times and market, contemporary art education and teaching is involved in the "information technology" art era.
\end{abstract}

Keywords-information technology; contemporary art education and teaching; effective application

\section{INTRODUCTION}

The continuous development of society and the advance of scientific culture will have a great influence on the art education field, and become the motive force for the development of art forms. We discuss art education and teaching all the time, however, the discussion basically focuses on the aspects such as method, objective and means of education and teaching round and round, which always stays in traditional teaching ideas, but does not conduct the exploration on art education and teaching structure. In the 20th century, with the development of science, emerging culture and new technology was born. As for technology in the late 20th century, information technology gradually became the mainstream of cultural development under this atmosphere. The era of information technology brings a new look to contemporary education. Traditional art education and teaching also has new innovation opportunities. The integration of information technology and art education and teaching will become the development trend of contemporary art teaching.

Therefore, effective application of information technology to contemporary art education is the frontier domain on which almost all developed countries are studying, and its development is also very fast, from computer technology, network and "photoelectric" science in narrow sense to modern art in broad sense, such as performance art, conceptual art, installation art and ready-made art, also including fashion culture, film, music and literature, etc. The combination of information technology and fashion art reflects people's consumption demand for continually enriching their perception and experience and their pursuit for spirit value in addition to material consumption in this creative economy era. The demand and pursuit cannot be neglected, and they fully reflect the value of the combination of information technology and fashion art. Therefore, information technology has become one of the most important creation means of contemporary art, and has become an important fact to which we must pay attention in studying and promoting contemporary art and art education and teaching.

\section{DEFINITION OF CONCEPT OF INFORMATION TECHNOLOGY}

Regarding to the concept of information technology, information technology is the generic terms of various technologies used for managing and processing information. It mainly uses computer science and communication technology to design, develop, install and implement information systems and application software. It mainly includes sensor technology, computer technology and communication technology. After the appearance of computers and the Internet, people have been used to their existence, and have started to gradually use them to work as well as process, exchange and disseminate information in various forms, e.g., online dissemination of books, commercial papers, journals, songs, film and TV, etc. through information technology. In colleges and universities or other organizations, the implementation of information technology, namely, informatization, has become a longterm strategic objective. It has been listed in the five-year plan or ten-year plan of almost all units. It is a type of system engineering. Its construction and management are involved in all departments subordinated to each unit. In colleges and universities construction, its application is involved in various fields such as teaching, scientific research, management and service. Its construction content includes multiple aspects such as infrastructure, information resources, application system, standard specification and management system. Successful completion of various projects in educational informationization construction engineering can be guaranteed with powerful measures. The "new" wording of information technology is appeared with the development of nowadays society. Digital art and virtual art, etc. which are brought by high-techs such as computer and network can be called "new". It can also be considered that it reflects the characteristics driven by science and technology and is continually changing. Moreover, information technology depends on different social, technological and cultural development levels and different reference content. After making a general survey of history, we can find that the wording of information technology has existed since long 
before. Most people regard it as a form that can realize culture technology utilizing means such as technology and electronic equipment. But it is not as simple as what people imagine after carefully analyzing. The artists, who want to break away from the inertial arts district to create and challenge the wording of western contemporary art, have always pursued new technology and new experiments, etc., and integrated information technology means in their practices. Therefore, information technology cannot be interpreted only from text level; it shall be analyzed in combination with relevant contents such as history and cultural background. Information technology is involved in many fields such as computer technology, art, sociology, science, philosophy and communication, and is a fusion of multiple disciplines. You can also say it is a new form and new means with new media and technology as a basic language. It is a new technology containing a brand new experimental spirit. Compared with traditional scientific culture, it has features such as open structure, multimedia concatenation, cross-disciplines and virtual reality.

\section{INFLUENCE OF INFORMATION TECHNOLOGY ON CONTEMPORARY ART EDUCATION AND TEACHING}

With the development of science \& technology and information technology, contemporary art education and teaching has also undergone huge changes. With the continuous renewal and change of education and teaching concept, course reform, learning method and way, etc., information technology has introduced modern and postmodern artistic concepts to artistic creation and contemporary art education and teaching. Aspects, such as paying attention to the combination of science \& technology and art, paying attention to the mutual assistance and collaborative communication of multiple disciplines, and introducing technology and teaching resources to the classroom, fully reflect that information technology plays a positive role in contemporary art education and teaching.

1. Information technology is accepted by contemporary art education concepts. With the development of science \& technology and information technology, the use of technologies including network is more common. All media arts can be the available resources of education and teaching.

2. Network plays an important role in contemporary art education and teaching. The construction of virtual art gallery, virtual classroom, virtual interactive course and electronic photo album cannot leave network. People can also understand art through network media channels and apply the resources from network into art teaching.

3. Software application promotes the development of contemporary art education and teaching. For example, various software, such as image processing software-Photoshop, CorelDRAW and Illustrator, digital sketching and drawing software--Painter, animation production software--Flash and plan-making software--Auto CAD and 3D software--3dmax, enriches the content of art education and teaching, and improve the students' creational means and level in art education and teaching.
4. Art education website and its theoretical research have been gradually applied and popularized. At present, since the website in the aspect of art education shall be built and managed by people with professional knowledge of art and artistic accomplishment, the development and research on art education websites are very few. There are very few excellent art education and teaching resources on the network. In the future, more and more people will devote to this industry, construct and improve art education and teaching websites and its theoretical research, and give its application value a full play.

\section{SignificANCE of EFFECTIVE APPLICATION OF \\ INFORMATION TECHNOLOGY TO CONTEMPORARY ART EDUCATION AND TEACHING}

Each revolution and breakthrough of information technology has irreplaceable influence on art itself and its education. Art and science are inseparable. The trace of science can be found throughout the development of human art form. For example, the earliest artistic creation of humans can be attributed to the cave painting in the Palaeolithic Period. The works of da Vinci in the Renaissance Period are incisive and vivid combination of arts and sciences. With the development of technologies such as image and TV in the late $60 \mathrm{~s}$, information technology occupies a very important position in social culture. The development of art widely applies the latest media information technology. Art continuously develops with high-tech as the background and creation means. With the change of art form and media technology, contemporary art tries to break the routine by selecting more media language, molding and technological means. Since the kinetic art presenting in the form of visual literature, such as science \& technology media, photography, camera shooting network, film and television, is easily accepted by mass social culture. They will soon become the route of transmission and ideal tool of contemporary art. In the 21 st century, when computer and network, etc. gradually became the center of mass cultural life, digital art time, virtual art, network art, interactive art, etc. have gradually became the core industry in the era of contemporary knowledge in the economy. From interactive media to digital high definition, from animation to mainstream industries such as online games, information technology is pushed into core competitive fields. The perfect combination of contemporary art education \& teaching and information technology which is closely related to science and technology is undoubtedly the most important form promoting the reform of contemporary art education and teaching.

The essential change of contemporary education innovation is the embodiment of information technology. The innovation of education is to solve the quality and mode problem of current talent training. It can involve aspects such as education and teaching methods, teaching means, learning concepts, course objectives and course content. If information technology is reasonably applied to teaching, the trained talents in information era will have corresponding innovation consciousness, ability and spirit. The concept of strengthening art education informationization, which has 
always been put forward by College of Arts of colleges and universities and art circles, is not empty talk. The essential difference between traditional art and it has been distinguished from concept. What traditional art education emphasizes is effort and the one for one help \& drive type education. The teacher teaches hand by hand, while the student learns in a one-to-one method. The efficiency of this teaching method is extremely low. We all can understand that in fact, what contemporary art education emphasizes is excavating the students' potential for art, focusing on the artistic perception of each student, and focusing on training their creativity in the aspect of art. The teachers may have very excellent artistic culture and teaching skills, have their own painting style and aesthetic tendency. If the teachers always teach by personal example as well as verbal instruction, impart their concept and perception, etc. to students, and educate a similar themselves, doesn't it violate the principle of innovation and obliterate the students' creativity in a sense? Therefore, how to effectively use the concept and characteristic of information technology to serve the student is the question that the worker of contemporary art education and teaching shall carefully think about.

At present, the rejection and postposition phenomena is due to the fact that some teachers do not understand the essence of the application of information technology to art teaching, and do not master information technology hinder the application and teaching of information technology, which is very unfavorable for the development of themselves and the students. Information technology develops with the development of society, economy and culture, and its development is identical to the current development tendency. Information technology will finally deeply impact the mode, method, concept, thinking and education system, etc. of contemporary art education and teaching. Therefore, if we want to educate creative and high-quality artistic talent conforming to the law of social development, we shall effectively apply information technology to the whole contemporary art education and teaching system. Only in this way can we effectively complete the real mission of art education and teaching, and allow information technology to truly exert its value and strong innovation function in art education and teaching. Information technology and art education $\&$ teaching supplement each other.

\section{SugGestions on EFFECTIVE APPLICATION OF INFORMATION TECHNOLOGY IN CONTEMPORARY ART EDUCATION AND TEACHING}

\section{A. Led by Art, Assisted by Technology}

Although information technology relies on the development of technology and art, we shall clarify that it still is an art form, while technology is a means of expression or creation. They are not equal. The creative process or pattern of manifestation of information technology must rely on digital technology to combine art affective thinking with rational thinking to generate a new form of art. Key teaching points of information technology shall focus on the penetration of teaching contents of digital technology to the creation and motivation of students' artistic imagination, not merely information technology. True artworks shall be excellent works created with the premise of concept and thinking of artists and assisted by technical support. Therefore, information technology in contemporary art education courses shall pay attention to the education of students' art thinking and innovation abilites.

\section{B. Laying Emphasis on Traditional Art, Daring to Inheritance and Innovation}

At present, the intervention of information technology production methods to art does not directly change the art elements of traditional art, but provides wider production space for artists, and adds more expressive effects to the requirement of the artist. Computer or software is used to better express the creator's originality, conception or imagination in traditional information technology works, but it is simple and fixed, which is adverse to the expansion of the students' creative thinking and affects the education of the students' operational ability. Some artistic conceptions of traditional painting cannot be matched or surpassed by information technology. Therefore, in specific teaching process's, we shall pay attention to traditional art forms such as freehand sketching, enlighten the students to explore Chinese traditional culture and innovate, combine with traditional Chinese culture to enrich artistic creation materials, and guide the students to reasonably apply the means of information technology without following suit or plagiarism, maintain the attitude of "take the essence, discard the dregs", carry on traditional Chinese culture and create the artistic works reflecting the native characteristic.

\section{Continuous Introduction of New Technology, Timely Application and Teaching}

Information technology develops with the development of technology. Contemporary art education and teaching shall continuously introduce new technology with the development of times. With continuous popularization of new technology, information technology will doom to be affected. For example, with the appearance of cloud computing, 3G, 4G, digital panel and digital screen, etc., digital drawing board, etc. also appear in the contemporary art education and teaching classroom. The students can utilize these high-techs to operate the instrument to reflect their thinking and complete their creation. Its advantages not only lie in fast, but also lie in easy modification, save and output. Such a creation is free and flexible and has a close combination with traditional drawing. In future days, information technology will change quickly with the development of technology, and these new technologies and new equipments shall also be timely applied to art education and teaching.

\section{CONCLUSION}

To sum up, information technology and relevant studies are very active at present, and have achieved outstanding achievements. Effective application of information technology to the field of contemporary art education and teaching undoubtedly enlightens and expands the students' thinking and will improve the effect of task-based learning. It 
can vividly express the teaching content, improve the students' skills, facilitate the students' knowledge-mastering, make the teachers easily express their teaching thought, concept, method and content, and make the students easily and intuitively understand the teaching content. In the aspect of education and teaching, the acquisition of knowledge and the creation of scenes will be more convenient; in the aspect of education and teaching content, language, characters and 3D scenery, or the process of virtual reality can be more coordinated and describable. In the aspect of education and teaching means, it will provide the students with the scene and the thinking material which directly transmits the message. Therefore, perfecting and constructing the innovative strategy appropriately integrating information technology with contemporary art education and teaching, avoiding various new problems and new conditions arisen in the application of contemporary information technology, and realizing mutual assistance of information technology and contemporary art education and teaching are of vital importance for the development of contemporary art education and teaching in China.

\section{REFERENCES}

[1] Li Sida. The History of Digital Media Arts. Tsinghua University Press. Beijing, 1st edition of 2008.

[2] Wang Li. Review of Information Technology Development. Tongji University Press, 2009.

[3] Gu Zhenqing. Information technology: new trend of digital times [J]. Gallery, 2010, (9): 84-87

[4] Zhang Jian. Discussion on Basic Connotation of Art Discipline Construction from the Angle of Management [J]. Nanjing Arts Institute Fine Arts and Design, 2010(6).

[5] Zhang Yanxiang. Information Technology [M]. Beijing: Science Press, 2011

[6] Mu Lan. Art Education Being a Great Social Project-On the Functions of Colleges' Art Education towards the Social Development for the Thirty Years since the Reform and Openness [J]. Press Circles, 2010(3).

[7] Cao Tianquan. Information Technology Experimental Art and Design [M]. Changsha: Hunan Fine Arts Publishing House, 2010 